\title{
The Scope and Needs of Medical Research*
}

\author{
By Sir Walter M. Fletcher, K.B.E., C.B., F.R.S.
}

$\mathrm{I}^{\mathrm{N}}$ $\mathrm{N}$ this outline I have tried to show the wide sweep and scope of the group of studies properly called medical research. In spite of the widely scattered fields over which it ranges, this work is joined in an organic unity because it has ultimate reference always to the nature and the needs of the living human body. At almost every point will be found interrelations between one part of the work and another, and between the various groups of workers in this extended army. While it is served of course by the medical sciences, physiology, pathology, bacteriology, it calls in increasing degree for intensive studies in the more primary sciences of chemistry and physics. Medicine, in fact, using the word in a wide sense, is already being served by a great army of workers, of which a large and increasing number may have no medical degrees and no direct relation to the medical profession.

When the Medical Research Council began its work eighteen years ago, then, and indeed for some years later, rickets was regarded by many of the best authorities in Europe as a chronic infective disease of which the infective agent was unidentified. It was called on the Continent the ' English disease' because it was first described in England and because of its abundance in our smoky cities. The disease consists most prominently in the failure of the calcifying process that gives hardness and strength to the bones and to the teeth, and the rickety child is stunted, deformed and enfeebled in various degrees. Before the War it was estimated that in our cities at least one child in every three had obvious signs of rickets. Dr. Mellanby discovered, by laborious experimental work, that rickets is simply a deficiency disease due to the lack in the food of a particular constituent, now called vitamin D. The proper supply of this prevented rickets or rapidly cured rickets already present. Familiar now as this is, even to laymen, it was greeted at first and for some years by much scepticism in many medical circles.

This discovery has led to a remarkable series of developments. It had been found that sunshine upon the body also prevented or cured rickets, that it was the short ultra-violet rays that had this action, and that it could also be produced by artificial light. But these rays cannot penetrate more than a tiny thickness of skin, and their action must therefore be upon something at or very near the surface. Were the rays producing vitamin D from something on the skin surface ? The vitamin was known to be associated with fats; it was an obvious guess that the light might produce it from the protective grease secreted upon the skin surface. A chief constituent of this is a fat called cholesterol. A loud 'cry' from what had now become an international pack of hounds announced that this was the right line and that irradiation of cholesterol gave vitamin $D$. But almost at once a more sagacious 'hound' (if I may continue that im-

* Continued from p. 192.

No. 3276 , VoL. 130] pertinent metaphor for Dr. Rosenheim at the National Institute for Medical Research) found with Mr. T. A. Webster that it was not cholesterol itself that gave this result but a related substance, present with it in much smaller quantities. This, after exchange of results and ideas with Prof. A. Windaus of Göttingen, was identified as a sterol called ergosterol, previously known only as the characteristic sterol of certain fungi and of yeast.

Now the problem became one for intensive study by physicists, organic chemists and biologists working in intimate collaboration. A team of this kind, working under the general leadership of Dr. R. B. Bourdillon at the National Institute for Medical Research, obtained a crystalline substance of very high antirachitic activity by the physical process of distillation in a high vacuum ; and another team under Prof. Windaus, in Germany, obtained a very similar substance by a selective chemical reaction. Both of these, however, proved to be compounds of the vitamin with inert substances; and Dr. R. K. Callow, of the National Institute group, found a method of separating the vitamin from either as a crystalline ester, from which the pure vitamin can be liberated. It proves to be itself a sterol, differing from the parent ergosterol only in a detail of the structural arrangement of its atoms, and it has been given the chemical name 'calciferol'. In pure form this has almost incredible biological potency. A single ounce of it would suffice to give a full daily ration for a million growing children.

It is to be noted that this devotion of physicists and chemists to a medical problem has done more than assist medical knowledge. It has yielded additions to both physical and chemical methods. A new form of photoelectric microphotometer which multiplied five-fold the speed of observations was produced in its course, together with a new type of spectrograph. Important new contributions have been made and are still being made to our knowledge of the pure chemistry of the group of sterol compounds. In deciding between alternative possibilities of structure for these complex molecules, the chemist is becoming more and more dependent on the physicist for measurements made by the methods of $\mathrm{X}$-ray analysis.

Now this progressive work, interesting as it is, is not only a clever physico-chemical exploration of academic interest. The results of this intensive laboratory work take on at once a direct bearing upon the practical needs of the community. Accurate knowledge of the vitamin allows adequate standardisation of its amount in different foodstuffs, in terms of a fixed standard of reference. Its artificial production, moreover, brings into action, or should bring into action, the medical administrator, who should be concerned to see that so long as social or economic factors maintain, as they do, an effective shortage of the natural sources of the vitamin among our city populations, a supply 
of it by means of the new methods we now have at command shall be made available for every growing child and every child-bearing mother in the country.

There still remains for study the attractive physico-chemical problem of how it is exactly that this calciferol molecule exerts its special influence upon the living cells of the intestinal walls and exactly why, without it, they cannot do their work of effecting the passage of calcium salts into the blood from the food but not back again. Of this we now know almost nothing. Here our task is to attempt further steps towards better knowledge of the mysterious microcosm of the living cell sub. stance.

Other fascinating vistas are in sight. Only in the last few weeks workers in the physico-chemical laboratory at Cambridge have found some evidence that the action of particular wave-lengths of light in developing vitamin $\mathrm{D}$ from its precursor substance may not be, as we had been thinking, an isolated phenomenon. They have obtained some indications that, just as for this, so in the case of two other vitamins-each in its own way indispensable for animal life--particular wave-lengths of light may produce the vitamin from its precursor while other wave-lengths close to them destroy it. What we know already of the chemistry of the vitamins having these special relationships to light shows that they belong to widely different types of chemical compounds. If the indications just given should be confirmed, it will seem to be, so to speak, more than a mere coincidence that in two or three different directions at least the animal cell has come to be vitally dependent upon different individual chemical substances, of which each has these remarkable photochemical properties. We should have to consider that we have here perhaps taken our first step towards knowledge of a phase of evolutionary development that has not been dreamed of hitherto, a development made manifest in a highly specialised and detailed adaptation of living matter to its age-long environment of light.

In quite another direction, the growing demands of medical research for intensive physico-chemical studies may be illustrated. Among the varieties of parasitic life that infest the animal body, I mentioned the so-called viruses that cause devastating diseases in man, in animals, and in plants. The loss they cause in life and in money has a magnitude almost beyond calculation. They cause smallpox, measles, infantile paralysis, and many other diseases in man. They cause foot-and-mouth disease of cattle, swine fever, fowl-pox, and other devastating plagues in animals. They cause ruinous diseases in vegetable crops of many kinds, from potatoes in Great Britain to bananas in the tropics. They are called 'viruses' at present because that commits us to no decision as to their nature. What do we know about them ? In a fluid containing them they can be shown to be freely suspended and particulate bodies, for the fluid can be freed from them by rapidly spinning it in a tube so that the particles are driven to one end of it. The bacteria themselves vary widely in size as animals do. None of them can be seen with the unaided eye, and taking the largest as enlarged to the size of a horse the smallest would then be represented by a mouse-and would be near the extreme limit of our highest powers of direct microscopic vision. The viruses are so small, however, that they pass through porcelain filters that retain all bacteria, and they are just upon or beyond the border-line of direct vision by ordinary microscopic means.

Here again medical research has had to call for the intensive application of new physical methods of study. By using the shorter wave-lengths of ultra-violet light the limits of clear microscopic vision can be extended, though this involves using quartz instead of glass throughout the optical apparatus, and obtaining photographic images instead of using direct vision by the eye. It is desirable to photograph the virus bodies in their natural state undisturbed by chemical agents or by stains which by coating their surface alter their apparent size. These methods are already being successfully applied at the National Institute for Medical Research by Mr. J. E. Barnard, who has been foremost in developing them. Another physical problem has been to devise suitable filters with apertures of known size and uniformity so that the different viruses may be graded in order of magnitude and the work of separating them in the laboratory made constant and accurate. This problem has been largely solved already by Dr. W. J. Elford, also at the National Institute, who has found how to produce accurately graded and uniform filters by making collodion films under precisely controlled conditions.

Many of the known viruses have already been arranged in an order of size, and the results gained by optical and filtering methods, which are constant, agree closely where they can be compared. They show that the viruses vary in size nearly as widely as the bacteria do. The largest are close in size to the smallest bacteria, and they descend to the virus of foot-and-mouth disease, of which the particles are little larger than the colloidal aggregates of oxyhæmoglobin in solution. There is probably not room in each particle for more than two or three hundred protein molecules. They can be present in immense number, and yet very few of them are enough to carry full potency. The fluid from a case of foot-and-mouth disease can be diluted ten million times and yet be potent to reproduce the disease.

There are many reasons for considering the viruses to be the smallest forms of life and for allowing them to be living organisms. But there are many unsolved difficulties here. The particles are far smaller than the simplest living cells which have hitherto been regarded as the smallest organisations of living matter endowed with specific character and the power of self-production. It is not certain that a virus can multiply outside a living animal or plant cell : inside it they may multiply with such rapidity as to make it tempting to think that the new particles are being formed not by the growth and a doubling subdivision of their 
own substance, but directly, and by some more rapid transformation of matter, out of the substance itself of the living cell containing them. In other words, it may perhaps be as true to say that the disease causes the virus as that the virus causes the disease.

Here again we notice how great is the intellectual interest offered to the physico-chemical student, quite apart from any incentive given by the gigantic practical benefits that will certainly be the reward of successful work in this field. It may be that in the study of these minute forms we are destined to find new clues to some of the most fundamental properties of living matter, and to express them in terms of physics and chemistry. It is perhaps just as likely that we may find ourselves able instead only to express physics and chemistry at this point in terms of life.

It is obviously most urgently desirable that we should increase our knowledge of these tiny forms and the laws of their behaviour as rapidly and fully as possible, if only with the direct utilitarian object of protecting the life and property they attack upon such an immense scale. We have to remember, too, that beyond a doubt some forms at least of malignant disease can be propagated by minute particles of matter which have all the known characters of the viruses. That being so, it is hard not to believe that the right clue to the problem of cancer lies here, and it is in fact being devotedly pursued from that point of view.

I might give many other examples of the great refinements now attained in many directions of biological and medical work. For study of the electrical changes in rapid muscular movement, the physiologist Einthoven introduced the string galvanometer which has been so useful in the hands of Sir Thomas Lewis and others in recording and analysing the successive events in the beat of the heart, normal or disordered. This instrument has passed as a contribution from biology to the regular uses of the physical laboratory. New devices of amplification by the physicists, on the other hand, have allowed Dr. Matthews at Cambridge to follow and measure the curve of electric change due to the passage of an impulse along a single nerve fibre, while Dr. E. D. Adrian there obtains an audible record by a loud-speaker of the impulse, for example, which passes along the optic nerve of a fish when a brief shadow flits across its retina. Prof. A. V. Hill follows the course of the heat changes due to the train of transient and minute chemical changes in nerve fibres that propagate the nervous impulse and measures them with an accuracy expressed in millionths of a temperature degree. The biologist, if given two samples of crystallised egg albumen from the eggs of a duck and hen respectively, can tell, by means of a biological test, which of them comes from which bird with great rapidity and certainty, though the detection depends on a subtle difference of molecular pattern far beyond the reach of any analysis by the chemist. Dr. Todd, at the National Institute at Hampstead, again, has shown that the interactions of the blood between fowl and fowl can be so used as to enable the biologist if he desires it to identify any given hen and its family from any other hen in the world. No organic chemist has ever dreamed of performing in such subtlety as that.

Medical progress, however, is greatly hampered by various circumstances that keep from its services many of the able men who are best fitted to enjoy giving their life-work to advancing it.

One of the most serious of these is the unfortunate and harmful tendency both in the schools and in the universities to segregate physicists and chemists on one hand from biologists on the other. At the schools this is largely the result of the scholarship system. It is found easier to cram clever boys along narrow specialist lines in physics and chem. istry for scholarships at the universities, while the universities have never taken effective action so to use the scholarship system as to secure a wellbalanced scientific education for scholarship candidates. The result is twofold. The cleverer boys are diverted from biology, while the biologists, if any, must give up proper training in the physical subjects and themselves specialise narrowly if they are to have any chance of scholarship success. The system of university examinations at both Oxford and Cambridge encourages still further this segregation of the sciences, and at Cambridge changes in regulations during the last twenty years have made the position worse rather than better. These are not only personal views drawn from $\mathrm{my}$ own experience; the same opinions have been strongly expressed by Lord Chelmsford's Committee, appointed in 1930 by the Prime Minister to consider the obstacles which stand in the way of the education and supply of biologists for work in Great Britain and overseas.*

I must not enter further upon this educational question now. I want only to urge here that the general cause of medical research suffers greatly from the present wide and unnecessary divorce, during the earliest stages of education and onwards, between those taught on the physical side and those upon the biological side. It is wholly indefensible on any ground that schoolboys and undergraduates who have special aptitudes for physical inquiry should be confined by a faulty system to the study of non-living matter only The problems of the living cell are at least as attractive to a keen mind as those of non-living matter, and they demand perhaps greater rather than less manipulative and analytical skill, because of the instability of the living substance that is studied.

Medicine has always been the mother of sciences, and we may remember that it was from the body of medicine, namely from the schools of physiology, and not from schools of organic chemistry, that biochemistry was born and developed as an organised university discipline. It has been found indeed as the result of experience that the man trained narrowly in organic chemistry does not in general make the best biochemist. Without earlier acquaintance with the problems of living things, he

Report of the Committee upon Education and Supply of Biologists. H.M. Stationery Office Publications, 63-75, 1932. Price $1 s$.

No. 3276, VoL. 130] 
is less likely to break new ground than the biologist starting far behind him in purely chemical equipment. There is pressing need now for a parallel development of bio-physics, not necessarily, or even desirably, as a separate discipline, but by a breaking down of the present artificial educational barriers between physics and physiology, barriers so unworthy of the Greek spirit of which those very names remind us.

I must not stay to speak of still another set of conditions that handicap medical progress. of those biologists who pass on to hospital work and the study of disease as such, many who are among the fittest to make new knowledge in the sphere of clinical medicine are tempted to turn aside from the arduous path of new investigation, either because of the absorbing human interest of professional work or again because of their financial needs or desires.

The mastery over non-living matter which physical science has given us has transformed all the conditions of human life within a century, but the conveniences offered by improved transport and improved communications have brought only super- ficial changes, and it is doubtful whether they have done on the whole greater service or disservice to the happiness and well-being of mankind. Our improved powers of producing wealth, as the whole world is now observing, seem already to have outrun lamentably our powers either of wisely using or even of retaining it. It is better mastery over living matter, and the improvement of the bodily and mental powers of man, that are needed for the real betterment and enrichment of the race. By powers of a kind that we are already in process of gaining by medical research we may hope to transform human life in ways almost unimagined now and to make a new world indeed.

Without entering into dreams of the far future we know that here and now the campaign of medical research is improving our estate. Its progress and success have immediate interest for all of us and the highest claims upon the goodwill of all mankind. It is a campaign to diminish pain, to lessen the waste of human effort and human life, and to enrich and enlarge the powers of the human body and mind.

\section{York Meeting of the British Association}

$\mathrm{T}^{\mathrm{H}}$ HE full programme of the York meeting of the British Association is approaching completion, and should be in the hands of members very shortly. A change of practice has been instituted with the view of economy and greater convenience. The " Programme and Daily Timetable" will embody the usual features both of the Association's list of transactions and of the socalled local programme formerly issued by the authorities at the place of meeting. Between these two publications there was always a measure of overlapping; moreover, the local programme was never in the hands of members until their arrival at the meeting. Now, following the practice initiated at last year's centenary meeting, when the whole organisation was centred at Burlington House, it becomes possible to place fuller advance information in the hands of nembers whose intention to attend, and postal addresses, are known.

Another and still more important change of practice with the same objects is initiated this year. It had become the custom, as is well known, for local committees to prepare handbooks for the successive places of meeting. Some of these have become standard reference-books of material value; on the other hand, the series followed no definite plan, and these books, again, were issued only at the meeting, and were sometimes very costly to produce. It is known that they did not always receive from members the attention they deserved: there is a case on record of a copy of the local handbook being seen on a second-hand bookstall in the place of meeting almost immediately after its issue. For the present year, a short "Scientific Survey of York and District" has been prepared by recognised authorities through the London office, with the collaboration of the appropriate sectional officers and the York executive. This also will be issued, so far as possible, to members in advance, and they will thus have the opportunity of priming themselves with information about the locality before they visit it. It is intended afterwards to include this "Survey" in the Annual Report, and if the present issue is found to form a satisfactory model, there will gradually accumulate, as the Association meets in successive centres, a systematic series of local scientific studies.

In these directions, at least, the Association has travelled far from the practice of twenty years ago, when the meeting was announced by a single leaflet, and members were left to find all other information at the meeting itself. Certainly the Association has become more businesslike (if the epithet may be permitted) in the formulation and announcement of its programmes. The main lines of the sectional transactions are laid down at the joint meeting of the organising sectional committees in January. The value of this meeting, which was initiated at the instance of the former general treasurer, the late Dr. E. H. Griffiths, has been, from the point of view of administration, immense, and it is believed to be the general opinion that it offers a most useful occasion for the really hard labourers in the Association's vineyard to keep in personal touch during the interval between the annual meetings.

As a result, the principal features of the meeting were known in broad outline when the "Preliminary Programme" was issued and noticed in NATURE for April 30, p. 642. Not many important corrections are made. The title of Lord Rothschild's presidential address to Section D (Zoology), not then announced, is now known to be "The Pioneer Work of the Systematist". The evening discourses by Sir Arthur Hill and Mr. C. C. Paterson have been transferred from the Exhibition Hall, which is found unsuitable for lanterns and demonstrations, to the less commodious but more 